\title{
Neuro-anesthetic Management of Craniotomy-surgery in Removal Tumor Multiple Meningioma Patients: A Case Report
}

\author{
Kulsum Kulsum ${ }^{1 *(D)}$, Taufik Suryadi ${ }^{2}$ iD \\ ${ }^{1}$ Department of Anesthesiology and Intensive Therapy, Faculty of Medicine, Universitas Syiah Kuala, the Zainoel Abidin \\ Hospital, Banda Aceh, Indonesia; ${ }^{2}$ Department of Forensic Medicine and Medicolegal, Faculty of Medicine, Universitas Syiah \\ Kuala, the Zainoel Abidin Hospital, Banda Aceh, Indonesia
}

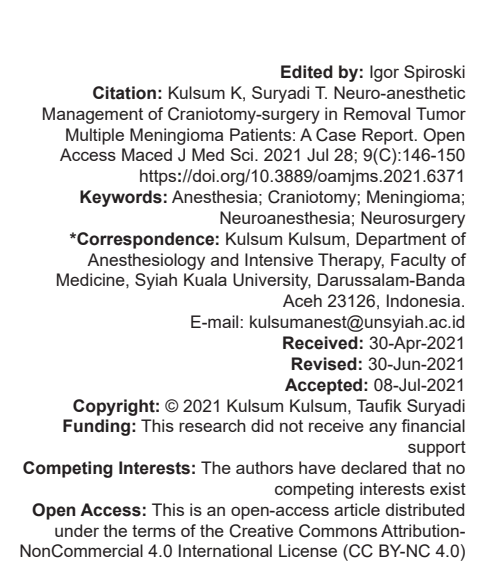

\section{Introduction}

Meningioma is a challenge for neurosurgeons worldwide because of its malignancy nature, and the expected surgical results are perfect after total excision. The very narrow range of errors makes surgery on meningioma more attractive. Nevertheless, sometimes, this presents a mixed picture and unusual complications [1]. Meningioma is an extra-axial tumor originating from the arachnoid membrane cells [1], [2]. These tumors often occur in multiple locations where arachnoid cells are present between the brain and bone, the ventricles, and along the spine [3]. These lesions can occur at any age, but most commonly in the elderly. Meningioma incidence in women is higher than in men, with a 2: 1 intracranial ratio and 10: 1 in the spine [1], [2], [3]. Most meningioma commonly benign, limited, develop slowly and can be treated surgically according to the location of the lesion. The most common location is in the parasagittal area [3]. The clinical symptoms that arise generally depend on the anatomical location involved. The three main symptoms that often occur are headache, altered mental status, and paralysis [1], [2], [3].

In addition to facilitating surgery, anesthetists also need to perform neuroanesthesia to control intracranial pressure (ICP) and brain volume, protect nerve tissue from injury and ischemia by implementing brain protection techniques, and reduce bleeding during the operation [4], [5]. Several things are essential to avoid during surgery, namely, hypoxemia, hypercapnia, anemia, and hypotension because they will harm the central nervous system and surgery results. It is essential to maintain brain autoregulation and response to $\mathrm{CO}_{2}$ to prevent ICP. Cerebral blood flow (CBF) is maintained at a mean arterial pressure (MAP) of 50-150 mmHg. Exceeding this limit, even with maximal dilation or maximal constriction of the cerebral blood vessels, CBF will passively follow the cerebral perfusion pressure (CPP). If $\mathrm{CBF}$ is significantly reduced (MAP $<50 \mathrm{mmHg}$ ), cerebral ischemia can occur. Above normal limits (MAP >150 mmHg), the pressure will damage the constriction of blood vessels, and CBF will rise suddenly. There is damage to the 
blood-brain barrier, and there is cerebral edema and possible cerebral hemorrhage [6], [7].

Intracranial components consist of brain tissue, blood, and cerebrospinal fluid. The volume composition of these three components can change according to Monroe Kellie's law, but the total volume is always constant because the intracranial volume is always the same. Therefore, the increasing volume of one component will be followed by a decrease in the volume of another component. Good neuroanesthesia includes the prevention of disruption of each of the intracranial components [8], [9].

Inhalation anesthetic techniques have been widely accepted in neurosurgical management, but they can decrease vascular resistance, particularly cerebral vascular resistance, resulting in increased CBF and ICP. In cases with increased ICP, the inhalation anesthetic technique will make the ICP higher, thereby reducing $\mathrm{CPP}$, increasing the risk of cerebral ischemia, which can cause brain damage [10].

The total intravenous anesthesia technique uses propofol/dexmedetomidine and analgesic drugs (remifentanil or fentanyl), can reduce CBF, decrease ICP, maintain brain perfusion pressure and decrease cerebral metabolism oxygen rate (CMRO2) known as "Coupling Flow Metabolism" to protect brain tissue from damage [11]. This case report will discuss the neuro-anesthetic management of craniotomy surgery in the removal of multiple meningiomas. This case was interesting because of full of challenges for the neurosurgeon and neuroanesthesia. The way a neurosurgeon controls the bleeding and makes the outcome better. For the neuroanesthesia, how to maintain the stable hemodynamic by maintaining the CPP was adequate, reducing the $\mathrm{CBF}$, maintain the normal autoregulation, decreasing the CMRO2, keeping the cerebral delivery oxygen (CDO2) was adequate, making the slack brain relaxing tumor.

\section{Case Report}

A 50-year-old female presented with complaints of full-body spasms since $10 \mathrm{~min}$ before admission to the hospital, full-body spasms with eyes staring upward with a seizure duration of about $20 \mathrm{~min}$, a patient with a history of meningioma brain tumor and had surgery 4 years ago, a history of seizures previously there after surgery for 5 times, the last seizure was about 4 months ago. The patient had fever since 1 day before hospital admission. History of high blood pressure is denied. The patient has comorbid type II diabetes mellitus. A history of asthma and allergies to food and drugs was also denied. On physical compos mentis patient with a blood pressure of $130 / 90 \mathrm{mmHg}$, a regular pulse rate of $90 \mathrm{times} / \mathrm{min}$, a breath rate of $18 \mathrm{times} / \mathrm{min}$, and an oxygen saturation of $98 \%$. Mallampati 1, good flexion and extension movements of the neck and temporomandibular joints.
Auscultation of the chest, a versicular breath sounds, and no wheezing and rhonchi were found - laboratory tests within normal limits. Chest radiograph with a posterioranterior position is normal limits. Electrocardiography (ECG) with left axis deviation is normal with a heart rate 100 times/min sinus rhythm. The contrast and noncontrast computerized tomography (CT) scan of the head showed a hyper-dense lesion in the left frontal and parietal bone area measuring $6.0 \mathrm{~cm} \times 4.0 \mathrm{~cm} \times 5.3 \mathrm{~cm}$ and multiple lesions on the left side of the cerebellum pontine angle (CPA) with a size of $3.0 \mathrm{~cm} \times 4.0 \mathrm{~cm} \times$ $2.7 \mathrm{~cm}$, in the right CPA the diameter was $1.8 \mathrm{~cm}$. In the frontal lobe, the diameter was $1.3 \mathrm{~cm}$ multiple meningiomas. Deviation of the midline to the right was about $1 \mathrm{~cm}$ from the previous about $1.5 \mathrm{~cm}$. Defect in the right frontal bone (Figure 1). The patient was diagnosed with multiple meningiomas, with the American Society of Anesthesiology 3 of physical status [2].

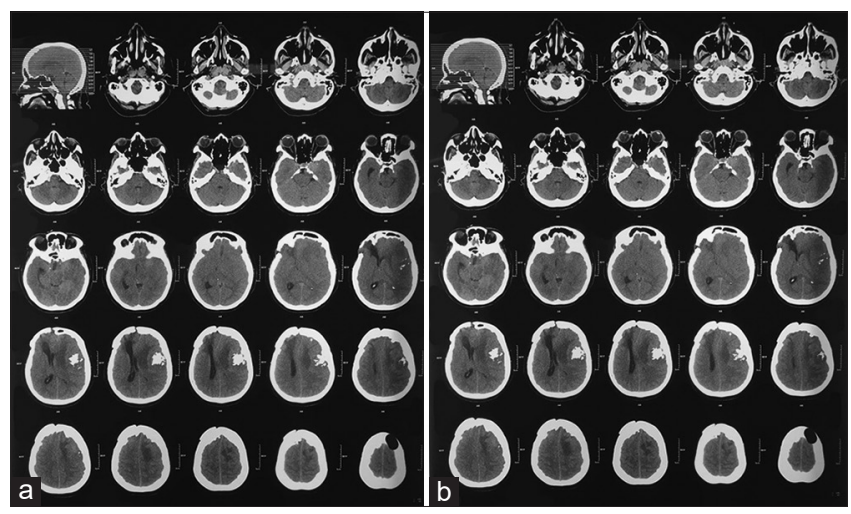

Figure 1: Non-contrast computerized tomography (CT) scan (a), CT scan by contrast (b), revealed multiple meningiomas, perifocal tumor edema, midline shift, cerebral edema were found

In anesthesia management in the operating room, the patient is positioned in a supine and gives hyperventilation approximately 20 times/min while being given oxygen $(\mathrm{O} 2)$ through a facemask. The patient was induced with $120 \mathrm{mg}$ of fentanyl, $150 \mathrm{mg}$ of propofol, and $50 \mathrm{mg}$ of rocuronium. Sevoflurane was started at 1.2 volume $\%$. Intubation was performed using a Macintosh laryngoscope with a 7.0 size non-kinking endotracheal tube (ETT) with a balloon. Maintenance of anesthesia with $1.2-2 \%$ sevoflurane with a ratio of $50 \%$ oxygen: $50 \%$ air, continuous propofol at a dose of $50 \mathrm{mcg} / \mathrm{kg} / \mathrm{min}$, and continuous rocuronium.

Monitoring during surgery is done by evaluating systolic, diastolic, mean arterial blood pressure, endtidal carbon dioxide $\left(\mathrm{CO}_{2}\right)$, oxygen saturation, and ECG wave. Urine output through a urine catheter. The operation lasts $4 \mathrm{~h}$, with the patient in the supine position. The amount of bleeding was $1050 \mathrm{cc}$, and the diuresis was 700 cc. Patients received 1800 cc crystalloid, $40 \mathrm{mg}$ mannitol, and $10 \mathrm{mg}$ dexamethasone, $535 \mathrm{ccs}$ packed red cell performed surgery for $3 \mathrm{~h}$ with a transbasal approach. When the periosteum is opened, the dura does not appear tense, and when the dura is opened, a slack brain appears. The tumor was excised 
under a microscope. The dura mater and other layers are closed until the operation is complete.

Postoperatively, the patient is admitted to the intensive care unit (ICU). On the $1^{\text {st }}$ day in the ICU, the patient entered the ICU at 1:00 p.m. on a ventilator control (pressure control, $\mathrm{FiO} 250 \%$, respiratory rate 12 times/ min, P-inspiration 12, PEEP 5, VT 350-370 cc, Oxygen saturation (SatO2) 99\%). While in the ICU, the patient received fentanyl $25 \mathrm{mcg} / \mathrm{h}$. Other therapies in the ICU include ceftriaxone, omeprazole, citicoline, propofol, dexamethasone, and mannitol.

\section{Discussion}

Meningioma neoplasms are classified based on the source, degree of anaplasia, and tumor location. The general classification of meningioma based on the World Health Organization (WHO) criteria divides meningioma into three groups, as shown in Table 1 [3]. All of these factors influence prognosis and management strategies. About 35,000 new tumor cases are diagnosed each year in the United States, of which $85 \%$ are primary brain tumors. Primary brain tumors account for $55-60 \%$ of all supra-tentorial tumors. Primary brain tumors included neuroepithelial tumors (35\%), meningioma (15\%), and pituitary adenomas (8\%). The incidence of meningioma is 7.8 per 100,000 per year, but only $2.5 \%$ are symptomatic [11], [12].

Table 1: Meningioma grading based on the WHO criteria

\begin{tabular}{ll}
\hline Type & Characteristic \\
\hline Benign meningioma & - Histological variant other than the clear cell, chordoid, \\
(WHO Grade I) & papillary, or rhabdoid \\
& - Lack criteria of atypical and anaplastic meningioma \\
Atypical meningioma & - Mitotic index $\geq$ four mitoses/10 high-power field (HPF) \\
(WHO Grade II) any of & - Brain invasion \\
three criteria & - At list 3 of 5 parameters: \\
& a. Increase cellularity \\
& b. High nuclear/cytoplasmic ratio (small cells) \\
& $\begin{array}{l}\text { c. Prominent nucleoli } \\
\text { d. Uninterrupted pattern-less or sheet-like growth }\end{array}$ \\
& $\begin{array}{l}\text { e. The fact of spontaneous necrosis (i.e., not induced by } \\
\text { embolization or radiation) }\end{array}$ \\
& - Mitotic index $\geq 20$ mitoses/10 high-power field \\
Anaplastic (malignant) \\
meningioma (WHO Grade & - Anaplasia (sarcoma or melanoma-like histology) \\
III) (either of two criteria) &
\end{tabular}

Meningioma is an extra-axial tumor that is often faced by neurosurgery and has been studied for the last two decades. Meningioma formed from cells that line the outside of the arachnoid membrane, meninges, or stem cells. In general, meningioma originates from the meninges and connects directly to the meninges on the brain's surface. Most of the meningioma grows slowly, and complaints and disorders result from pressure on the area around the mass. The three most common complaints are headache, altered mental status, and limb weakness. Most meningioma can be treated surgically, especially if the tumor location allows for complete extraction of the tumor and is accompanied by dura layer adhesions [13], [14].
Neoplasms in the central nervous system can cause both generalized and focal neurological disorders. Patients with tumors causing increased ICP may experience headache, nausea and vomiting, ataxia, syncope, and visual and cognitive impairments. Focal neurological signs are presented due to the mass compression in the surrounding area. Visual disturbances occur in a predictable pattern according to the location of the mass to the optic nerve, optic tract, optic radiation, and visual cortical area [15], [16]. Evaluation of a patient suspected of having an intracranial mass begins with the history and neurological examination. Radiological examination is essential for determining the patient's diagnosis and location of the tumor and postoperative assessment of patients with a supratentorial period.

Compared with $\mathrm{CT}$, magnetic resonance imaging images of soft tissue give better results [17], [18]. The main purpose of anesthesia, in this case, is not only to facilitate surgery but also to control ICP and brain volume, prevent secondary brain injury, and reduce the occurrence of bleeding during surgery. Factors to avoid include hypoxemia, hypercapnia, anemia, and hypotension. Brain autoregulation and response to $\mathrm{CO}_{2}$ must be maintained to prevent it. The three intracranial components include brain tissue, blood, and cerebrospinal fluid. The volume composition of these three components can change according to Monroe Kellie's law, but the total volume is always constant because the intracranial volume is always the same. A volume decrease of one component will follow a volume increase in another component. Autoregulation of blood flow to the brain under normal conditions ranges from $50 \mathrm{cc} / 100 \mathrm{~g} / \mathrm{min}$ with a basal brain oxygen consumption of $3.3 \mathrm{cc} / 100 \mathrm{~g} / \mathrm{min}$ and a glucose consumption of $4.5 \mathrm{mg} / 100 \mathrm{~g} / \mathrm{min}$. This condition can occur when the MAP is maintained between 50 and $150 \mathrm{mmHg}$. MAP below $50 \mathrm{mmHg}$ can cause ischemia in brain tissue, while pressures above $150 \mathrm{mmHg}$ will cause damage to the blood-brain barrier resulting in brain edema or severe bleeding. In the case of brain tumor removal, a target $\mathrm{PaO} 2$ of $100-200 \mathrm{mmHg}$ is expected. The provision of high oxygen levels with a $\mathrm{PaO} 2>200 \mathrm{mmHg}$ should be avoided because cerebral vasoconstriction can occur and cause brain tissue ischemia [3], [6], [10]. Changes in the partial pressure of $\mathrm{CO}_{2}$ in the arteries (PaCO2) will result in changes in brain blood flow because $\mathrm{CO}_{2}$ is a potent vasodilator in brain blood vessels. Every $\mathrm{mmHg}$ change in $\mathrm{PaCO} 2$ between 25 and $80 \mathrm{mmHg}$ will change brain blood flow by about $4 \%$.

In brain tumor surgery, the $\mathrm{PaCO} 2$ is maintained between 25 and $30 \mathrm{mmHg}$ to decrease CBF. $\mathrm{PaCO}_{2}$ pressures below $20 \mathrm{mmHg}$ should be avoided as they can cause severe vasoconstriction and cause brain tissue ischemia [4]. Propofol is widely used in the induction of anesthesia and sedation in neuro-intensive care. Several studies have shown that propofol has a protective effect 
on the brain. Propofol decreases CBF (30\%), CMRO2 (30\%), and ICP. The CPP also decreases because propofol has a powerful hypotensive effect. The mechanism of action of propofol is to facilitate the inhibition of neurotransmission mediated by gamma-aminobutyric acid (GABA). In this case, titrated propofol $100 \mathrm{mg}$ was given to a patient weighing $70 \mathrm{~kg}$. The effect of propofol administration on the cardiovascular system can lead to a decrease in blood pressure by an average of $20 \%$ and a decrease in systemic vascular resistance by $26 \%$, and the result is a decrease in cerebral perfusion. However, this decrease can be prevented by giving propofol by titration and giving fluids before induction. This patient was given a co-loading fluid of $10 \mathrm{cc} / \mathrm{kg}$ body weight or 700cc [19].

Muscle relaxants are known to increase CBF, but the agents that increase CBF the least are vecuronium and rocuronium, so they are the drugs of choice for neurosurgical surgery. In this case, rocuronium muscle relaxant $50 \mathrm{mg}$ was given to a patient weighing $70 \mathrm{~kg}$. Rocuronium was chosen in this case because it is the competitive muscle relaxant that has the fastest onset of action, reportedly reacting within 2 min with an intermediate duration of action. Reported to have minimal cardiovascular effects; at high doses, it has a mild vagolytic effect. Rocuronium is mainly eliminated in the liver and a small part in the kidneys [4], [6].

The inhalation anesthesia used was sevoflurane $0.8 \%$ with a ratio of 50 oxygen: 50 air. The use of $50 \%$ oxygen flow is done to prevent the $\mathrm{PaO} 2$ pressure above $200 \mathrm{mmHg}$. N2O can directly vasodilate cerebral blood vessels and increase CBF, but this effect can be reduced by hyperventilation (PaCO2 30-35 mmHg). In some studies, $\mathrm{N} 2 \mathrm{O}$ has no protective effect on brain neurons and can lead to vacuolization of the endoplasmic reticulum and mitochondria. N2O can also cause complete disinhibition of GABA receptors. In patients with folic acid deficiency, the use of $\mathrm{N} 2 \mathrm{O}$ can cause spinal cord degeneration and inhibit the electrophysiological recovery of cells. However, the adverse effects vary when $\mathrm{N} 2 \mathrm{O}$ is used in combination with other inhalation anesthesia, with or without hypocapnia [4], [7].

Sevoflurane was used in this case because the effects of cerebral vasodilation and increased CBF were the lowest of all the anesthesia gases. Sevoflurane also has a neuroprotective effect in the form of antiapoptosis [6]. The decrease in cardiac output by sevoflurane is also lower than isoflurane or halothane, thus avoiding excessive fluid administration or the use of vasoconstrictors. Sevoflurane is also safe to use in cases of asthma because it does not irritate the airway. Early extubation following the use of sevoflurane facilitates early neurological examination [8].

Lidocaine is local anesthesia in the amide class. Lidocaine can be administered intravenously at a dose of $1-1.5 \mathrm{mg} / \mathrm{kg}-\mathrm{BW}$ to prevent the increased hemodynamic response and airway response to intubation. The start of action of lidocaine is $60-90 \mathrm{~s}$. In this case, lidocaine was not administered [20]. Mannitol $20 \%$ is an osmotic diuretic with an osmolarity of $1086 \mathrm{mOsm} / \mathrm{L}$, with a dose of $0.25-0.5 \mathrm{~g} / \mathrm{kg}$, reducing ICP rapidly. Mannitol was administered before drilling for the cranium.

Furosemide or loop diuretic can also be given at a dose of $0.5-1 \mathrm{mg} / \mathrm{kg}-\mathrm{BW}$. In this case, frusemide was not given because the brain tissue had seen slack with the administration of mannitol [4], [9]. Another measure that can be done to prevent an increase in ICP is to position the patient's head at an elevation of $15-30^{\circ} \mathrm{C}$. Mild hypothermia, that is, a temperature of $33-35^{\circ} \mathrm{C}$, can cause a decrease in blood flow to the brain by about $5 \%$ at any change of $10^{\circ} \mathrm{C} \mathrm{[4],} \mathrm{[7].} \mathrm{Postoperatively,} \mathrm{the}$ patient's head is maintained in a supine position, in a neutral position, not tilted to the left or right and is not hyperextended or hyperextended. Blood pressure is maintained within auto-regulatory limits, and the hematocrit is maintained at not far from 33\% [3], [10].

The difference between the day to day techniques with this case is to keep the principle of neuroanesthesia procedure as such as CPP, cerebral metabolic rate oxygen (CMRO2), CDO2, CBF, ICP, Cerebral Autoregulation, and slack brain. The pitfalls and the problems in the neuroanesthesia approach are lack of monitoring. We combined intravenous and inhalational anaesthesia instead of choosing one technique because the drug-like propofol does not provide enough effect for $3 \mathrm{~h}$ of surgery. We did not extubate this patient because of avoiding problem when transferring the patient to the ICU. The goals in neuro-critical care post-operative are to maintain the CPP adequate, the cerebral metabolic oxygen rate decrease, CBF decrease, and ICP decrease. The outcome of this patient was good; Glasgow Coma Scale 15, hemodynamic was stable, no seizure, can transfer to the room.

The strength of this case report is this is a rare case in our hospital and full of challenges for the neurosurgeon and neuroanesthesia. Neuroanesthesia management was difficult, so we need knowledge, skills, and medical equipment for procedure and monitoring. The limitation of this case report was the patient in the high risky procedure, but the facilities are provided not advance hemodynamic monitoring. The skills of neurosurgeon also are the key to the successful removal of tumor procedure when bleeding control. The good management of neuroanesthesia will support the success of maintaining stable hemodynamic and better outcome.

\section{Conclusion}

The optimal conditions for meningioma tumor surgery are challenging for anesthetists — various 
neuroanesthesia approaches, including patient positioning and optimal neuroanesthesia management to minimize edema and bleeding. The "ABCDE" neuroanesthesia approach consists of Airway, namely ensuring a safe airway; Breathing, by providing adequate ventilation and oxygenation; circulation, which is stabilizing the cardiovascular system; drug, which is avoiding drugs and anesthetic actions that increase ICP and environment, namely, maintaining a mild temperature/hypothermia. A wide variety of medications are available for general anesthesia management. Therefore, the anesthetist must know the effects of each drug used to maintain the patient's hemodynamic condition and achieve a flaccid state of the brain tissue.

\section{References}

1. Hafez MM, Bary TH, Ismail AS, Mohammed MA. Frontolateral keyhole craniotomy approach to anterior cranial base. ZUMJ. 2013;1(19):6-8.

2. Sanai N, Surghrue ME, Shangari G, Chung K, Berger MS, McDermottMW. Risk profileassociated with convexitymeningioma resection in the modern neurosurgical era. J Neurosurg. 2010;112(5):913-9. https://doi.org/10.3171/2009.6.jns081490 PMid:19645533

3. Roosiati B, Yarlitasari D, Harahap S, Rahardjo S. TIVA on craniotomy for removal of recurrent tumors. JNI. 2012;1(4):269-77.

4. Cottrell JE, Young WL. Cottrell and Young's Neuroanaesthesia. $5^{\text {th }}$ ed. St Louis: Mosby; 2010.

5. Gheorgita E, Ciurea J, Blanescu B. Consideration on anesthesia for posterior fossa surgery. Ruman Neurosurg. 2012;19(3):183-93

6. Flower $\mathrm{O}$, Hellings $\mathrm{S}$. Sedation in traumatic brain injury. Emerg Med Int. 2012;2:1-3.

PMid:23050154

7. Tan AK, Mallika PS, Aziz S, Asok T, Intan G. The importance of ophthalmic signs in the agnosis of suprasellar meningioma-a case report. Malaysian Family Phys. 2009;4(1):26-9.

PMid:25606155
8. Hemmings $\mathrm{HC}$. The pharmacology of intravenous anaesthetic induction agent: The primer. Anaesthesia. 2010;12:6-7.

9. Rehatta NM, Hanindito E, Tantri AR, Redjeki IS, Soenarto RE, Bisri DY, et al. Anestesiologi dan Terapi Intensif. $1^{\text {st }}$ ed. Jakarta: Gramedia Pustaka Utama; 2019. p. 1212.

10. Butterworth JF, Mackey DC, Wasnick JD. Morgan and Mikhail's Clinical Anesthesiology. $5^{\text {th }}$ ed. New York: McGraw-Hill Education/Medical; 2013. p. 1383.

11. Bruder N, Ravussin PA. Supratentorial masses: Anesthetic considerations. In: Cottrell and Young's Neuroanesthesia. $5^{\text {th }}$ ed. Philadelphia, PA: Mosby Ersevier, Inc.; 2010. p. 188-96. https://doi.org/10.1016/b978-0-323-05908-4.10016-8

12. Wullur C, Bisri YD, Anaesthetic Management of a Patient with Large Supratentorial Brain Tumor Suspected Convexity Meningioma. JNI. 2014;3(2):96-102.

13. Bansal T, Hooda S. Obesity: Anesthetic implications and consideration-a review. Cumhuriyet Med J. 2014;36:409-14.

14. Hasan WM, Nasir YH, Zaini RH, Shukeri WF. Target-controlled infusion propofol versus sevoflurane anesthesia for emergency traumatic brain surgery: Comparasion of outcomes. Malays $J$ Med Sci. 2017;24(5):73-82.

PMid:29386974

15. Al-Hadidy AM, Maani WS, Mahafza WS. Intracrania meningioma. Jordan Med J. 2010;41(1):37-51.

16. Calvocoressi L, Claus EB. Epidemiology and natural history of meningioma. In: Pamir MN, Black PM, Fahlbusch $R$, editors. Meningiomas: A Comprehensive Text. New York: Saunders Elsevier; 2010. p. 61-77. https://doi.org/10.1016/ b978-1-4160-5654-6.00004-0

17. Cea-Soriano L, Wallander MA, Rodriguez G. Epidemiology of meningioma in the United Kingdom. Neuroepidemiology. 2012;39(1):27-34. https://doi.org/10.1159/000338081 PMid:22777495

18. Choy W, Kim W, Nagasawa D, Stramotas S, Yew A, Gopen Q, et al. The molecular genetics and tumor pathogenesis of meningiomas and the future directions of meningioma treatments. Neurosurg Focus. 2011;30(5):E6. https://doi. org/10.3171/2011.2.focus 1116 PMid:21529177

19. Fischer BR, Brokinkel B. Surgical management of skull base meningiomas-an overview. In: Monleon D, editor. Meningiomasmanagement and surgery. Shanghai, China: InTech; 2012. p. 85-102. https://doi.org/10.5772/30248

20. Mary AK Abuya JM, Chumba D, Koech FK. Association of radiological CT and MRI scan features to the histopathology of meningiomas in patients at major hospital in Eldoret Town, Kenya. Int J Adv Res. 2013;1(4):104-14. 